\title{
Avaliação espermática e da concentração de proteínas solúveis no plasma seminal de bodes da raça Alpina em regime de monta controlada
}

\author{
Leonardo Franco Martins ${ }^{1}$, Maria Cristina Baracat Pereira ${ }^{2}$, José Domingos Guimarães ${ }^{3}$, \\ Eduardo Paulino da Costa ${ }^{3}$, Thiago da Silva Silveira ${ }^{4}$, Ciro Alexandre Alves Torres ${ }^{5}$, Marcelo \\ Teixeira Rodrigues ${ }^{5}$, Vandberg Barbosa Braz $^{6}$
}

\author{
1 Universidade Estadual de Maringá - Campus de Umuarama. \\ 2 Departamento de Bioquímica - UFV. \\ ${ }^{3}$ Departamento de Medicina Veterinária - UFV. \\ ${ }^{4}$ Médico Veterinário Autônomo. \\ ${ }^{5}$ Departamento de Zootecnia. \\ 6 Veterinário autônomo.
}

RESUMO - Foram estudadas as relações entre a concentração de proteínas solúveis do plasma seminal, o teste hipoosmótico, a análise física e morfológica do sêmen e o desempenho reprodutivo de bodes da raça Alpina em regime de monta controlada. O experimento foi realizado durante os meses de fevereiro a abril de 2001. Foram realizadas 40 coletas de sêmen em quatro reprodutores adultos em regime de monta controlada. Em todas as coletas, além do exame físico e morfológico do sêmen, foram realizados os testes hipoosmóticos, isoosmóticos e a determinação da concentração de proteínas solúveis do plasma seminal. Foi detectada diferença entre os bodes na concentração de proteínas solúveis do plasma seminal, mas não houve diferença no teste hipoosmótico e no número de coberturas por prenhez. O teste hipoosmótico pode ser uma importante ferramenta para a avaliação de sêmen caprino, mas a concentração de proteínas solúveis do plasma seminal não pode ser utilizada como parâmetro para predizer a qualidade seminal e a fertilidade de bodes da raça Alpina utilizados em regime de monta natural.

Palavra-chave: caprino, concentração de proteínas do plasma, teste hiposmótico

\section{Reproductive performance, soluble proteins of the seminal plasm and hypoosmotic test in male goats of the Alpine breed under controlled mating}

\begin{abstract}
The relationships among soluble proteins of the seminal plasma, the hypoosmotic test, the physical and morphologic analyses of semen and the reproductive performance of male goats of the Alpine breed under controlled mating were studied using forty samples of semen from four adult male goats collected twice a week between February and April of 2001. Differences among male goats were observed for soluble protein concentration of the seminal plasma, but not for the hypoosmotic test and the pregnancy rate. These results suggest the hypoosmotic test may be used for the evaluation of goat semen, but the protein concentration of the seminal plasma can not be used as a parameter to predict the seminal quality and fertility of male goats of the Alpine breed.
\end{abstract}

Key Words: goats, hypoosmotic test, plasma protein concentration

\section{Introdução}

A necessidade de testes para predizer a capacidade reprodutiva de bodes em regime de monta natural vem crescendo, principalmente com a aquisição de bodes com potencial reprodutivo comprovado, uma importante ferramenta para aumentar os índices de produtividade na caprinocultura nacional (Ribeiro, 1997; Moreira et al., 2000). Diversos testes complementares são utilizados para predizer a fertilidade de machos, tendo em vista as altas correlações com o desempenho reprodutivo, além dos diferentes aspectos da qualidade seminal mensurados em cada teste. Novas técnicas têm sido desenvolvidas e estudadas juntamente com as análises de rotina (análise física e morfológica do sêmen) e com os testes complementares já utilizados para avaliação andrológica (por exemplo, o teste hipoosmótico utilizado com o de termorresistência) para melhor compreensão de seus resultados (Lena, 1997). O teste hipoosmótico avalia a integridade funcional da membrana plasmática dos espermatozóides e é utilizado para predizer um dos aspectos da qualidade seminal (Correa \& Zavos, 1994), haja vista a grande influência da atividade bioquímica das membranas 
plasmáticas dos espermatozóides nos processos de capacitação espermática e fertilização (Lebouef et al., 2006).

$\mathrm{O}$ estudo dos componentes bioquímicos do plasma seminal pode ser uma alternativa para avaliação do funcionamento do aparelho reprodutor e da qualidade seminal de bodes (Mendonza et al., 1989; Pinheiro et al., 1996a; Pinheiro et al., 1996b; Santos et al., 1998). As moléculas de alto peso molecular são responsáveis pelo efeito danoso aos espermatozóides, enquanto aquelas de baixo peso molecular estão relacionadas à ativação da motilidade espermática (Baas et al., 1983). As proteínas do plasma seminal em ruminantes são encontradas em agregados protéicos de alto peso molecular, que, na presença de citrato e em condições ácidas, separam-se em moléculas protéicas de baixo peso molecular (Al Somai et al., 1994). As funções do plasma seminal de caprinos consistem na ativação da motilidade (Howard et al., 1978), nas proteções contra a peroxidação dos lipídeos de membrana plasmática (Shoneck et al., 1996) e na capacitação espermática (Maxwell \& Johnson, 1999; La Falci et al., 2002). As concentrações dessas moléculas protéicas estão sob controle da estação do ano, para a qual ocorrem diferenças entre as estações reprodutiva e não-reprodutiva (La Falci et al., 2002).

Neste experimento, objetivou-se estudar as relações entre a concentração de proteínas solúveis do plasma seminal, o teste hipoosmótico, a análise física e morfológica do sêmen e o desempenho reprodutivo de bodes da raça Alpina em regime de monta controlada.

\section{Material e Métodos}

$\mathrm{O}$ experimento foi realizado no terço final do verão (fevereiro a abril) de 2001 no Setor de Caprinocultura do Departamento de Zootecnia da Universidade Federal de Viçosa, a 2045'20" S e 42 $52^{\circ}$ ' $40^{\prime \prime}$ W Gr, com altitude média de $752,5 \mathrm{~m}$, temperatura média anual de $20,9^{\circ} \mathrm{C}$, índice pluviométrico anual de $1.203 \mathrm{~mm}$ e clima com inverno seco e verão chuvoso (Ferreira et al., 1998). Os dados climatológicos da região de Viçosa foram cedidos pela estação climatológica principal do Instituto Nacional de Metereologia, situada no município de Viçosa.

Foram utilizados quatro reprodutores adultos da raça Alpina com 1,5 a 6 anos, criados em condições intensivas, com alimentação constituída de $50 \%$ de silagem de milho, $30 \%$ de milho desintegrado com palha e sabugo + $5 \%$ de uréia e $20 \%$ de polpa cítrica, obtendo-se um valor nutricional de 1,47\% de energia líquida (mcal), 11,68\% de PB, 30,88\% de FDN, $0,53 \%$ de Ca e $0,24 \%$ de P. O sal mineral e a água foram fornecidos ad libitum e o controle sanitário (anti-helmíntico e vacinação) foi realizado periodicamente no rebanho, conforme critérios estabelecidos no capril.

As coletas de sêmen foram realizadas duas vezes por semana, sempre à tarde, pelo método de vagina artificial, com auxílio de uma fêmea em estro induzido por meio da aplicação de estrógeno (cipionato de estradiol) (Merial Saúde Animal Ltda.), via intramuscular, em intervalos de dez dias. Durante o período experimental, foram obtidos 40 ejaculados. Além do exame físico-morfológico do sêmen, foram realizados os testes hipoosmótico e isoosmótico e a determinação da concentração de proteínas solúveis do plasma seminal.

$\mathrm{Na}$ avaliação física do sêmen, foram considerados o volume do ejaculado, a motilidade espermática progressiva retilínea, o turbilhonamento, o vigor e a concentração espermática, de acordo com os critérios preconizados pelo Colégio Brasileiro de Reprodução Animal - CBRA (1998). Uma gota de sêmen foi colocada sobre uma lâmina previamente aquecida a $37^{\circ} \mathrm{C}$, na qual se observou, com auxílio de microscopia óptica com aumento de 100x, o turbilhonamento (movimento em massa, em escala de 0 a 5). Após colocar uma gota de sêmen entre lâmina e lamínula, com aumento de $400 x$, verificaram-se a motilidade progressiva retilínea (percentual) e o vigor espermático (escala de 0 a 5). Posteriormente, acrescentaram-se $10 \mu \mathrm{L}$ do sêmen em $4 \mathrm{~mL}$ de solução formol-salina tamponada (Hancoch, 1957) para contagem das células espermáticas, utilizando-se câmara de Neubauer, e determinação da concentração espermática por $\mathrm{mL}$ e no ejaculado total.

Para a avaliação morfológica dos espermatozóides, foi adicionada uma alíquota do ejaculado suficiente para turvar a solução em um ependorff contendo $0,5 \mu \mathrm{L}$ de formolsalina tamponada. A avaliação espermática foi realizada em preparação úmida com auxílio de microscopia de contraste de fase com aumento de 1.000x. Foram contabilizadas 200 células por ejaculado e caracterizados os percentuais de defeitos espermáticos, segundo os critérios descritos por Blomm (1973), em defeitos maiores, menores e totais, para classificação dos animais de acordo com os critérios preconizados pelo CBRA (1998) em animais aptos ou não à reprodução.

O teste hipoosmótico foi realizado no sêmen in natura segundo o protocolo adotado por Revell \& Mrode (1994): uma amostra de $10 \mu \mathrm{L}$ de sêmen foi homogeneizada em $1 \mathrm{~mL}$ de solução previamente aquecida a $37^{\circ} \mathrm{C}$ e, posteriormente, foi incubada por 1 hora a $37^{\circ} \mathrm{C}$. Foram utilizadas duas soluções com osmolaridades de 100 e $290 \mathrm{mOsm} / \mathrm{kg}$ (isosmótica) para o sêmen (Sousa et al., 2000; Fonseca et al., 2001). Depois do período de incubação, uma gota da solução foi depositada sobre uma lâmina 
previamente aquecida em uma placa aquecedora $\left(38^{\circ} \mathrm{C}\right) \mathrm{e}$ colocada uma lamínula (também previamente aquecida) sobre a gota, sendo retirado o excesso de líquido com auxílio de papel-filtro. Foram contados 200 espermatozóides em microscopia de contraste de fase em aumento de $1.000 x$ sob uma gota de óleo de imersão, verificando-se o percentual de espermatozóides com o flagelo curvando-se junto à membrana plasmática expandida, conforme critérios de dobramento de cauda descritos por Revell \& Mrode (1994) para sêmen bovino.

Determinou-se a concentração de proteínas solúveis $(\mathrm{mg} / \mu \mathrm{L})$ das amostras de plasma seminal conservadas em nitrogênio líquido com o auxílio de um espectofotômetro, segundo protocolo preconizado por Bradford (1976). Após a avaliação física e a retirada de alíquota de sêmen para a análise morfológica, o ejaculado foi diluído em solução fisiológica $(0,9 \%)$ na proporção de $1: 9$ e centrifugado a $700 \mathrm{~g}$ durante 10 minutos à temperatura ambiente. Em seguida, foi envasado em palhetas médias $(0,5 \mathrm{~mL})$ e conservado em nitrogênio líquido $\left(-196^{\circ} \mathrm{C}\right)$ para posterior análise da concentração protéica.

As seguintes substâncias foram utilizadas no preparo do reagente: Coomassie Brilliant Blue G-250, etanol a 95\% e ácido fosfórico a $85 \%$. Em $50 \mathrm{~mL}$ de solução de etanol a $95 \%$, foram dissolvidos $100 \mathrm{mg}$ do reagente Coomassie Brilliant Blue e adicionados $100 \mathrm{~mL}$ de solução de ácido fosfórico a $85 \%$. A seguir, essa solução foi diluída até o volume de $200 \mathrm{~mL}$ com água tridestilada (solução estoque), previamente diluída em água tridestilada para volume final de $1.000 \mathrm{~mL}$ (cinco vezes o seu volume).
Com o uso de uma solução de albumina sérica bovina (BSA) diluída em solução fisiológica $(1 \mathrm{mg} / \mathrm{mL})$, foram feitas diferentes diluições para o preparo da curva padrão para o reagente. De cada diluição protéica, $100 \mathrm{~mL}$ foram adicionados em $1 \mathrm{~mL}$ do reagente diluído no qual se mediu a absorbância em espectofotômetro utilizando-se comprimento de onda de $595 \mathrm{~nm}$, com tempo de reação de 2 a 30 minutos. Após a determinação da curva padrão e o ajuste linear dos dados, foi obtida a equação para determinação da proteína total das amostras (Figura 1).

As amostras de plasma seminal, depois de descongeladas em banho-maria a $37^{\circ} \mathrm{C}$, foram acondicionadas em microtubos $(1,5 \mathrm{~mL})$ e centrifugadas a $150 \mathrm{~g}$ durante 5 minutos para a completa remoção dos espermatozóides. A seguir, $100 \mu \mathrm{L}$ do sobrenadante foram diluídos e homogeneizados em $900 \mu \mathrm{L}$ de solução fisiológica em tubo de ensaio e $100 \mu \mathrm{L}$ dessa solução final foram adicionados a $1 \mathrm{~mL}$ do reagente (previamente diluído) em tubo de ensaio. Após 2 minutos, o conteúdo foi depositado em cubetas de vidro para aferição da absorbância das reações e estimativa da concentração protéica desta solução com base na equação de regressão (Figura 1).

Os quatro bodes serviram um total de 63 cabras no período de 21 de fevereiro a 10 de abril de 2001. Os reprodutores foram utilizados sob regime de cobertura controlada, no qual as fêmeas eram levadas às baias de cada bode. O diagnóstico de gestação foi realizado 15 dias após o fim da estação de monta por meio de exame ultrasonográfico transabdominal (Ultra-som Pie-medical, modelo VET 200-Holanda), com transdutor de 5,0 MHz,

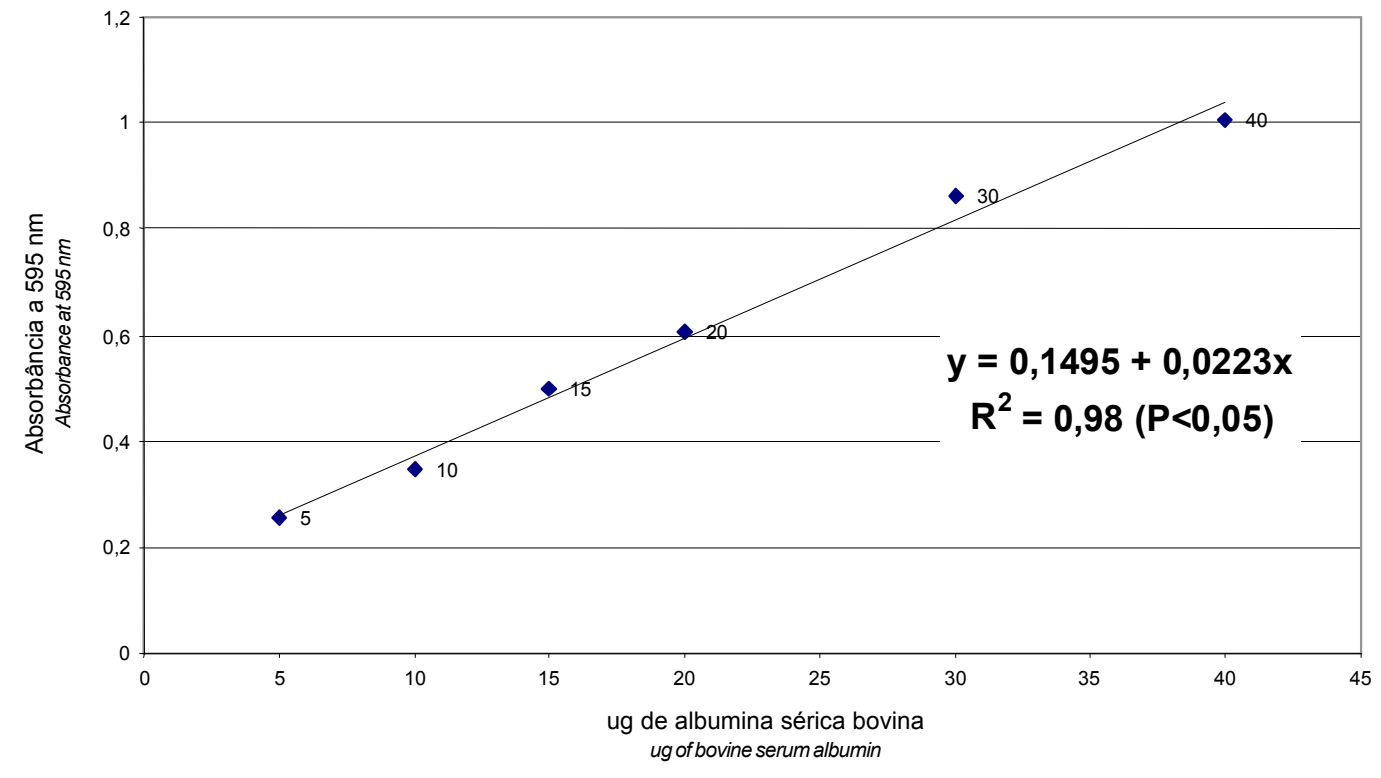

Figura 1 - Curva padrão para estimativa da concentração protéica.

Figure 1 - Standard curve to estimate the protein concentration. 
sendo registrada como prenhez positiva a observação da vesícula embrionária ou do feto.

Para a análise estatística, foi utilizado o sistema SAEG versão 7.0 (Euclydes, 1982), utilizando-se os testes Lilliefors e de Cochran-Bartlett para verificação de normalidade e da homogeneidade das variâncias das respostas das variáveis estudadas. As análises descritivas das médias, dos desvios-padrão e dos coeficientes de variação foram feitas para todas as variáveis estudadas. A análise de variância foi utilizada para avaliação dos efeitos dos bodes e dos dias de coleta sobre o teste hipoosmótico e a concentração protéica do plasma seminal. Ao ser detectado efeito pelo teste $\mathrm{F}$, os dados foram comparados pelo teste Tukey a $5 \%$ de probabilidade de erro. Os resultados das incubações nas soluções isoosmótica e hipoosmótica e o total de caudas dobradas na morfologia espermática foram comparados pelo teste t. A análise de regressão foi aplicada para determinação do comportamento das variáveis estudadas, durante o período experimental, e as correlações de Pearson foram realizadas para o cálculo das relações entre as características seminais e os testes realizados. Os dados relacionados, com o número de coberturas e a taxa de prenhez, foram avaliados em tabela de contingência e testados pelo teste do qui-quadrado a $5 \%$ de probabilidade de erro.

\section{Resultados e Discussão}

Neste estudo, não houve infuência dos dias de coleta sobre as características físicas dos ejaculados $(\mathrm{P}>0,05)$, mas foram detectadas diferenças na motilidade espermática progressiva retilínea, no vigor espermático e na concentração espermática por $\mathrm{mL}(\mathrm{P}<0,05)$ entre animais(Tabela 1$)$. $\mathrm{O}$ animal número 1 destacou-se nas características físicas do sêmen e o animal número 4 apresentou posição intermediária, não diferindo dos demais reprodutores $(\mathrm{P}>0,05)$ quanto à motilidade progressiva retilínea e ao vigor espermático (Tabela 1 ).

Os resultados obtidos para volume do ejaculado são coerentes com os encontrados na literatura consultada para bodes durante a estação reprodutiva (Karatzas et al., 1997; Sousa et al., 2000).

Os percentuais de defeitos espermáticos (menores, maiores, totais e de cauda dobrada) não diferiram entre as coletas $(\mathrm{P}>0,05)$. Entre os reprodutores, no entanto, houve diferenças nos percentuais de defeitos espermáticos maiores e totais $(\mathrm{P}<0,05)$; o bode 2 apresentou médias de defeitos maiores superiores às do bode 4 $(\mathrm{P}<0,05)$ e não diferiu dos bodes 1 e $3(\mathrm{P}>0,05)$. O mesmo comportamento foi observado para defeitos espermáticos totais (Tabela 2). Não foram observadas diferenças entre os bodes quanto ao percentual de defeitos espermáticos menores e de caudas dobradas encontradas no sêmen in natura $(\mathrm{P}>0,05)$ (Tabela 2$)$.

As médias dos percentuais dos defeitos maiores, menores e totais foram inferiores às encontradas por Santos (2001) na primavera e confirmam os achados de Vinha (1975), que observou diminuição dos defeitos espermáticos entre a primavera e o outono. $\mathrm{O}$ animal 2 foi o único inserido no experimento em repouso sexual. A redução do percentual de defeitos totais durante o experimento $(\mathrm{P}<0,05)$ justificase pelo fato de que os espermatozóides não ejaculados armazenados nos epidídimos e nas ampolas do ducto deferente são gradualmente eliminados pela urina e os não eliminados sofrem gradual degeneração, aumentando o percentual de defeitos espermáticos totais nos primeiros ejaculados após um período de repouso sexual (Hafez, 1995). Entretanto, o animal 3 apresentou decréscimo no percentual de defeitos espermáticos totais semelhante ao do animal 2 e não estava em repouso sexual. O percentual, no entanto, esteve dentro da normalidade (21\%), conforme os critérios preconizados pelo CBRA (1998), enquanto o do

Tabela 1 - Valores médios e desvios-padrão dos aspectos físicos do sêmen de bodes adultos da raça Alpina Table 1 - Means and standard deviations for the physical traits of semen of adult male goats of the Alpine breed

\begin{tabular}{|c|c|c|c|c|c|}
\hline $\begin{array}{l}\text { Bode } \\
\text { Goat }\end{array}$ & $\begin{array}{l}\text { Volume } \\
\text { Volume }\end{array}$ & $\begin{array}{l}\text { Motilidade } \\
\text { Motility }\end{array}$ & $\begin{array}{l}\text { Vigor } \\
\text { Vigor }\end{array}$ & $\begin{array}{l}\text { Turbilhonamento } \\
\text { Gross motility }\end{array}$ & $\begin{array}{c}\text { Concentração } \\
\text { Concentration }\end{array}$ \\
\hline 1 & $0,85 \pm 0,23^{\mathrm{a}}$ & $89 \pm 6,14^{\mathrm{a}}$ & $3,65 \pm 0,52^{\mathrm{a}}$ & $4,40 \pm 0,65^{\mathrm{a}}$ & $4706 \pm 812^{\mathrm{a}}$ \\
\hline 2 & $0,65 \pm 0,34^{\mathrm{a}}$ & $79,50 \pm 5,98^{b}$ & $3,10 \pm 0,31^{b}$ & $3,75 \pm 0,48^{\mathrm{a}}$ & $2810 \pm 933^{b}$ \\
\hline 3 & $0,63 \pm 0,41^{\mathrm{a}}$ & $78 \pm 6,32^{b}$ & $3,10 \pm 0,31^{b}$ & $3,75 \pm 0,58^{\mathrm{a}}$ & $2928 \pm 1060^{b}$ \\
\hline 4 & $0,70 \pm 0,27^{\mathrm{a}}$ & $85 \pm 5,77^{\mathrm{ab}}$ & $3,55 \pm 0,43^{a b}$ & $4,35 \pm 0,66^{\mathrm{a}}$ & $3377 \pm 1261^{b}$ \\
\hline Geral & $0,7 \pm 0,32$ & $82,87 \pm 7,32$ & $3,35 \pm 0,46$ & $4,06 \pm 0,662$ & $3455 \pm 1249$ \\
\hline \multicolumn{6}{|l|}{ Overall } \\
\hline $\mathrm{CV}$ & 45,87 & 8,84 & 14,01 & 16,29 & 36,15 \\
\hline
\end{tabular}

a,b,c Letras minúsculas diferentes na mesma coluna indicam diferença $(P<0,05)$ pelo teste Tukey a $5 \%$. Volume $=$ volume do ejaculado; Motilidade $(\%)=$ motilidade progressiva retilínea; Vigor = vigor espermático; Turbilhonamento = movimento em massa; Concentração = concentração espermática em milhão por $\mathrm{mL} ; \mathrm{CV}=$ coeficiente de variação.

a,b,c Different lower cases in the same column indicate statistical differences by Tukey test at $5 \%(P<0.05)$. Volume $=$ volume of the ejaculated; Motility $(\%)=$ spermatic motility; Vigor $=$ spermatic vigor; Gross motility; Concentration= spermatic concentration in millions by $\mathrm{mL} ; \mathrm{CV}=$ coefficient of variation. 
animal 2 superou os limites preconizados pelo CBRA (1998) na primeira coleta e, já na segunda coleta, estava dentro dos limites, diminuindo durante o período experimental. Todos os animais foram classificados como aptos à reprodução, conforme os critérios preconizados pelo CBRA (1998), com ejaculados de excelente qualidade durante todo o período experimental.

Nas análises dos testes complementares e de concentração de proteínas solúveis do plasma seminal, não foram detectadas diferenças entre as coletas $(\mathrm{P}>0,05)$. Assim como no percentual de caudas dobradas no sêmen in natura $(\mathrm{P}>0,05)$, os bodes não apresentaram diferenças

Tabela 2 - Valores médios e desvios-padrão dos aspectos morfológicos do sêmen in natura de bodes adultos da raça Alpina

Table 2 - Means and standard deviations for the morphological traits of semen of adult male goats of the Alpine breed

\begin{tabular}{lcccc}
\hline $\begin{array}{l}\text { Bode } \\
\text { Goat }\end{array}$ & $\begin{array}{c}\text { Maiores (\%) } \\
\text { Major }\end{array}$ & $\begin{array}{c}\text { Menores (\%) } \\
\text { Minor }\end{array}$ & $\begin{array}{c}\text { Total (\%) } \\
\text { Total }\end{array}$ & $\begin{array}{c}\text { Cauda (\%) } \\
\text { Tail }\end{array}$ \\
\hline 1 & $5,90 \pm 3,11^{\mathrm{ab}}$ & $6,60 \pm 5,90^{\mathrm{a}}$ & $12,50 \pm 6,34^{\mathrm{ab}}$ & $5,30 \pm 2,48^{\mathrm{a}}$ \\
2 & $10,05 \pm 6,00^{\mathrm{a}}$ & $7,20 \pm 2,45^{\mathrm{a}}$ & $17,25 \pm 7,53^{\mathrm{a}}$ & $6,85 \pm 3,78^{\mathrm{a}}$ \\
3 & $5,20 \pm 3,43^{\mathrm{b}}$ & $6,20 \pm 5,47^{\mathrm{a}}$ & $11,4 \pm 4,73^{\mathrm{ab}}$ & $4,35 \pm 3,49^{\mathrm{a}}$ \\
4 & $3,90 \pm 1,72^{\mathrm{b}}$ & $2,45 \pm 2,06^{\mathrm{a}}$ & $6,35 \pm 2,55^{\mathrm{b}}$ & $3,70 \pm 1,49^{\mathrm{a}}$ \\
Geral & $6,26 \pm 4,40$ & $5,61 \pm 4,56$ & $11,87 \pm 6,66$ & $5,05 \pm 3,08$ \\
Overall & & & & \\
CV & 70,32 & 81,41 & 56,14 & 61,06 \\
\hline
\end{tabular}

a,b,c Letras minúsculas diferentes na mesma coluna indicam diferença $(P>0,05)$ pelo teste Tukey a $5 \%$; Maiores $(\%)=$ defeitos maiores; Menores $(\%)=$ defeitos menores; Totais $(\%)=$ defeitos totais; Cauda $(\%)=$ defeitos de cauda; $\mathrm{CV}=$ coeficiente de variação.

$a, b, c$ Different different lower cases in the same column indicate statistical differences by Tukey test at $5 \%(P<0.05)$; Major $(\%)=$ major defects; Minor $(\%)=$ minor defects; Total $(\%)=$ total defects; Tail $(\%)=$ tail defects; $C V$ = coefficient of variation

Tabela 3 - Valores médios e desvios-padrão dos percentuais de caudas dobradas encontrados no sêmen caprino após incubação por 1 hora nas soluções isoosmótica e hipoosmótica

Table 3 - $\quad$ Means and standard deviations for the percentile of bent tails found after one hour incubation of goat semen in isoosmotic and hypoosmotic solutions

\begin{tabular}{lcc}
\hline $\begin{array}{l}\text { Bode } \\
\text { Goat }\end{array}$ & $\begin{array}{c}\text { Isoosmótico } \\
\text { Isoosmotic }\end{array}$ & $\begin{array}{c}\text { Hipoosmótico } \\
\text { Hypoosmotic }\end{array}$ \\
\hline 1 & $10,35 \pm 5,11^{\mathrm{a}}$ & $40,90 \pm 10,06^{\mathrm{a}}$ \\
2 & $8,85 \pm 3,98^{\mathrm{a}}$ & $30,10 \pm 8,27^{\mathrm{a}}$ \\
3 & $9,05 \pm 7,82^{\mathrm{a}}$ & $31,70 \pm 16,97^{\mathrm{a}}$ \\
4 & $7,15 \pm 2,46^{\mathrm{a}}$ & $30,70 \pm 8,31^{\mathrm{a}}$ \\
Geral & $8,85 \pm 5,15^{\mathrm{A}}$ & $33,35 \pm 11,89^{\mathrm{B}}$ \\
Overall & & 35,66 \\
CV & 58,24 &
\end{tabular}

a,b,c Letras minúsculas diferentes na mesma coluna indicam diferença $(\mathrm{P}<0,05)$ pelo teste Tukey a $5 \%$.

A,B Médias seguidas de letras maiúsculas na mesma linha indicam diferença $(\mathrm{P}<0,05)$ pelo teste Tuckey $5 \%$.

a,b,c Different lowercases in the same column indicate statistical differences by Tukey test at $5 \%(P<0.05)$.

A,B Different capital letters in a row indicate statistical differences by Tukey test at $5 \%$ $(P<0.05)$.
$(\mathrm{P}>0,05)$ no percentual de caudas dobradas após as incubações isoosmótica e hipoosmótica (Tabela 3 ).

O percentual de caudas dobradas, após a incubação isoosmótica, foi superior ao encontrado no sêmen in natura $(\mathrm{P}<0,05)$ (Tabela 2$)$. Esses resultados não corroboram os obtidos por alguns autores que concluíram que a incubação em solução isoosmótica não altera a morfologia da cauda dos espermatozóides (Rodriguez-Gil et al., 1994; Caiza et al., 1997; Vazquez et al., 1997; Vaz de Melo, 1999). Os percentuais de caudas dobradas na incubação isoosmótica e no sêmen in natura foram próximos durante o período de coleta, mas os coeficientes de variação foram altos $(58,24$ e 61,06$)$, o que pode ter influenciado os resultados do teste $t$ ao serem detectadas diferenças entre a incubação isoosmótica e os defeitos de cauda dobrada no sêmen in natura.

A correlação positiva entre o teste hipoosmótico e a motilidade espermática progressiva retilínea foi baixa $(0,28)$, corroborando os registros de Vaz de Melo (1999).

As altas temperaturas do ambiente provavelmente influenciaram a qualidade seminal, alterando o processo de maturação epididimária, comprometendo as estruturas da membrana plasmática dos espermatozóides (Huang et al., 2000; Santos, 2001) e diminuindo os dobramentos de cauda frente ao meio hipoosmótico. A média obtida neste experimento para o percentual de caudas dobradas após a incubação em solução hipoosmótica $(33,35 \%)$ foi inferior à registrada por Santos (2001) durante a primavera (57,2\%), como conseqüência das maiores médias e temperaturas máximas durante o verão (Ferreira et al., 1998). Sousa et al. (2000), utilizando a osmolaridade de $100 \mathrm{mOsm} / \mathrm{kg}$, também obtiveram média superior no percentual de caudas dobradas na incubação hipoosmótica $(84,9 \%)$. Todavia, esses autores utilizaram um protocolo diferente do adotado neste experimento, incubando 100 ul de sêmen em $1 \mathrm{~mL}$ de solução hipoosmótica durante 25 minutos e depois fixando o material em gluteraldeído a $2 \%$ para o esfregaço, sendo contabilizados 100 espermatozóides em microscópio de contraste de fase (1000 x). O tempo de incubação de 1 hora pode aumentar a osmolaridade da solução, em virtude da evaporação, e diminuir os dobramentos de cauda no teste hipoosmótico.

As médias de temperatura diária e umidade relativa do ar no período experimental foram $22,83^{\circ} \mathrm{C}$ e $80 \%$, respectivamente, e as médias do mês de março foram semelhantes. As coletas de sêmen foram realizadas à tarde, quando ocorrem mais freqüentemente as temperaturas máximas diárias (Ferreira et al., 1998). A média e o desvio-padrão das temperaturas máximas do período experimental foram 
Tabela 4 - Valores médios e desvios-padrão da concentração de proteínas solúveis do plasma seminal $(\mathrm{g} / \mathrm{dL})$ no sêmen de bodes adultos da raça Alpina

Table 4 - Means and standard deviations for the total protein concentration in the seminal plasm ( $\mathrm{g} / \mathrm{dL}$ ) of semen of adult male goats of the Alpine breed

\begin{tabular}{lc}
\hline $\begin{array}{l}\text { Bode } \\
\text { Goat }\end{array}$ & $\begin{array}{c}\text { Concentração }(\mathrm{g} / \mathrm{dL}) \\
\text { Concentration }\end{array}$ \\
\hline 1 & $1,67 \pm 0,57^{\mathrm{b}}$ \\
2 & $2,52 \pm 0,91^{\mathrm{ab}}$ \\
3 & $2,89 \pm 0,92^{\mathrm{a}}$ \\
4 & $3,07 \pm 0,809^{\mathrm{a}}$ \\
Geral & $2,4 \pm 0,59$ \\
Overall & 37,71 \\
CV & \\
\hline
\end{tabular}

Concentração = concentração de proteínas solúveis do plasma seminal (g/dL). $a, b, c=$ letras minúsculas diferentes na mesma coluna indicam diferença $(p<0,05)$ pelo teste de Tuckey a $5 \%$.

Concentration $=$ total protein concentration in the seminal plasm $(g / d L)$.

a, $b, c=$ different lower cases in the same column indicate statistical differences $(P<0.05)$ by Tukey test at 5\%.

$30,16 \pm 1,59$, semelhantes às médias do mês de março e corroborando os registros de Ferreira et al. (1998) para as temperaturas na região de Viçosa.

Não foi detectada diferença na concentração de proteínas solúveis do plasma seminal entre os dias de coleta $(\mathrm{P}>0,05)$. $\mathrm{O}$ bode 1 apresentou valores inferiores na concentração de proteínas solúveis do plasma seminal, não diferindo apenas do bode $2(\mathrm{P}>0,05)$. Os bodes 2,3 e 4 apresentaram os maiores valores e não diferiram entre si $(\mathrm{P}>0,05)$ (Tabela 4).

A concentração média de proteínas solúveis do plasma seminal registrada neste experimento (Tabela 4) foi baixa em relação à descrita na literatura consultada. Pinheiro et al. (1996b) obtiveram médias e desvios-padrão de concentração protéica total do plasma seminal de bodes da raça Alpina de 4,08 $\pm 0,12 \mathrm{~g} / \mathrm{dL}$ durante a estação chuvosa. Santos et al. (1998) também obtiveram médias superiores em bodes Moxóto e mestiços PardoAlpinos x Moxotó de 5,14 $\pm 1,09$ e 4,65 $\pm 0,6 \mathrm{~g} / \mathrm{dL}$, respectivamente. Ressalta-se que Pinheiro et al. (1996b) e Santos et al. (1998) utilizaram, para determinação da concentração protéica, o método do biureto, com sensibilidade diferente do utilizado neste experimento. Segundo Scope (1987), diferentes valores na concentração protéica são determinados pelo protocolo utilizado e pelas proteínas que compõem a solução protéica.

No total de coberturas por prenhez, não foram observadas diferenças entre os reprodutores $(\mathrm{P}>0,05)$. Todavia, o bode 1 apresentou, em números absolutos, os menores valores de concentração de proteínas solúveis do plasma seminal (Tabela 4), melhores aspectos físicos do sêmen (Tabela 1) e maior percentual de cauda dobrada no teste
Tabela 5 - Desempenho reprodutivo de bodes da raça Alpina em regime de monta controlada

Table 5 - $\quad$ Reproductive performance of male goats of the Alpine breed under controlled mating

Bode Fêmeas cobertas Total de prenhez Índice de prenhez

Goat Mated females Pregnant females Pregnancy rate

\begin{tabular}{llll}
\hline 1 & $4(80 \%)^{\mathrm{a}}$ & $1,25^{\mathrm{a}}$
\end{tabular}

$2 \quad 5 \quad 2(40 \%)^{\mathrm{a}} \quad 2,5^{\mathrm{a}}$

$3 \quad 27 \quad 18(66,66 \%)^{\mathrm{a}} \quad 1,44^{\mathrm{a}}$

$426 \quad 18(69,2 \%)^{\mathrm{a}} \quad 1,5^{\mathrm{a}}$

Índice de prenhez = número de fêmeas cobertas pelo número de fêmeas gestantes durante a estação.

$\mathrm{a}=$ letras minúsculas iguais na mesma coluna indicam igualdade $(P>0,05)$ pelo teste de $\mathrm{X}^{2}$ e ANOVA.

Pregnancy rate $=$ number of females mated by the number of females pregnant during the breeding season.

$a=$ equal lower cases in the same column do not indicate $(P>0.05)$ differences by the $X^{2}$ test and ANOVA.

hiposmótico (Tabela 3), em relação aos demais animais (Tabela 4), e teve o melhor índice de prenhez (Tabela 5). Foi registrada correlação alta e negativa $(0,44)$ entre a concentração de proteínas solúveis do plasma seminal e o teste hipoosmótico.

Os resultados das análises da concentração de proteínas solúveis do plasma seminal realizadas neste estudo não apresentaram relação com a fertilidade dos machos e, portanto, o método utilizado não foi eficiente em predizer a qualidade seminal dos reprodutores. A presença de várias substâncias protéicas no plasma seminal com diversas funções no metabolismo espermático torna necessária sua identificação, caracterização e quantificação para se entender os resultados.

\section{Conclusões}

O teste hipoosmótico pode ser uma importante ferramenta para avaliação de sêmen caprino, haja vista a relação com a motilidade espermática progressiva retilínea, que é uma das principais características físicas do sêmen de reprodutores. Neste estudo, a concentração de proteínas solúveis do plasma seminal não se correlacionou com a fertilidade dos animais em regime de monta controlada nem com as características físicas e morfológicas do sêmen e o teste hipoosmótico.

\section{Literatura Citada}

AL SOMAI, N.; VISHWANATH, N.; SHANNON, P.E. et al. Low molecular weight components in bovine semen diffusate and their effects on motility of bull sperm. Journal of Reproduction and Fertility, v.41, p.165-171, 1994.

BLOMM, E. The ultrastructure of some characteristic sperm deffects and a proposal for a new classification of the bull spermiogram. Nordisk Veterinarer Medicin, v.25, p.383-391, 1973. 
BRADFORD, M.M. A rapid and sensitive method for the quantitation of microgram quantities of protein utilizing the principle of protein-dye binding. Analitical Biochemistry, v.72, p.248-254, 1976 .

CAIZA, C.F.I.; RIGAU, T.; BONET, S. et al. Subjecting horse spermatozoa to hipoosmotic incubation: effects of ouabain. Theriogenology, v.47, p.765-784, 1997.

COLÉGIO BRASILEIRO DE REPRODUÇÃO ANIMAL - CBRA. Manual para exame andrológico e avaliação de sêmen animal. 2.ed. Belo Horizonte: CBRA, 1998. 49p.

EUCLYDES, R.F. Sistema de anãlise estatística e genética SAEG. Viçosa, MG: Universidade Federal de Viçosa, Central de Processamento de Dados, 1982. p.68.

FERREIRA, W.P.M.; SOUSA, C.F.; ARAÚJO, H.B. Comportamento das temperaturas extremas de Viçosa-MG. In: Atmosfera e água. Secretaria de Planejamento e Desenvolvimento, 1998. v. 3, p. 27-32.

FONSECA, J.F.; TORRES, C.A.A.; SANTOS, A.D.F. et al. Hypoosmotic swelling test in goat spermatozoa. Revista Brasileira de Reprodução Animal, v.25, p.436-438, 2001.

HAFEZ, E.S.E. Reprodução animal. 6.ed. São Paulo: Manole, 1995. p. 146-156.

HANCOCH, J.L. The morphology of boar spermatozoa. Journal of the Royal Microscopical Society, v.76, p.84-97, 1957.

HUANG, S.Y.; KUO, Y.H.; LEE, Y.P. et al. Association of heat shock protein 70 with semen quality in boars. Animal Reprodution Science, v.63, p.231-240, 2000.

KARATZAS, G.; KARAGIANNIDIS, A.; VARSAKELI, S. et al. Fertility of fresh and frozen-thawed goat semen during the nonbreeding season. Theriogenology, v.48, p.1049-1059, 1997.

LA FALCI, V.S.N.; TORTORELLA, H.; RODRIGUES J.L. et al. Seasonal variation of goat seminal plasma proteins. Theriogenology, v.57, p.1035-1048, 2002

LEBOUEF, B.; LE VERN, Y.; FURSTOSS, V. et al. Response of goat sperm to hypoosmotic steps modeled probit analysis. Animal Reprodution Science, v.36, p.265-274, 2006.

LENA, M. Assessing the quality of raw semen: a review. Theriogenology, v.48, p.523-530, 1997

MENDONZA, G.; WHITE, G.I.; CHOW, P. Studies of chemical components of angora goat seminal plasma. Theriogenology, v.32, p.455-466, 1989 .

PINHEIRO, R.R.; MACHADO, R.; PINHEIRO, A.A. et al. Níveis de cálcio, fósforo, magnésio e $\mathrm{pH}$ do sêmen de caprinos no nordeste do Brasil. In: REUNIÃO ANUAL DA SOCIEDADE BRASILEIRA DE ZOOTECNIA, 33., 1996, Viçosa, MG. Anais... Viçosa, MG: Sociedade Brasileira de Zootecnia, 1996a. p.419-421.

PINHEIRO, R.R.; MACHADO, R.; PINHEIRO, A.A. et al. Parâmetros bioquímicos do plasma seminal de três tipos raciais de caprinos do nordeste do Brasil. In: REUNIÃO ANUAL DA SOCIEDADE BRASILEIRA DE ZOOTECNIA, 33., 1996, Viçosa, MG. Anais... Viçosa, MG: Sociedade Brasileira de Zootecnia, 1996b. p.416-418.
REVELL, S.G.; MRODE, R.A. An osmotic resistance test for bovine semen. Animal Reprodution Science, v.36, p.77-86, 1994.

RIBEIRO, S.D.A. Caprinocultura: criação racional de caprinos. São Paulo: Nobel, 1997. 318p.

RODRIGUEZ-GIL, J.E.; MONTSERRAT, A.; RIGAU, T. Effects of hipoosmotic incubation on acrossome and tail structure on canine spermatozoa. Theriogenology, v.42, p. 815-829, 1994.

SANTOS, A. Características reprodutivas e congelabilidade do sêmen de reprodutores das raças Alpina e Saanen submetidos ao manejo de fotoperíodo. Viçosa, MG: Universidade Federal de Viçosa, 2001. 73p. Dissertação (Mestrado em Zootecnia) - Universidade Federal de Viçosa, 2001.

SANTOS, D.O.; AZEVEDO, H.C.; SALLES, H.O. et al. Efeito da insulação escrotal sobre os constituintes do plasma seminal de bodes. Arquivo Brasileiro de Medicina Veterinária e Zootecnia, v.50, p.283-286, 1998.

SCOPE, R.R. Protein purification: principles and practice. 2.ed New York: Springer-Verlag, 1987. p.276-283.

SOUSA, J.P.F.; BARBAS, J.P.; FERREIRA, G.M.B.C. et al. Variação anual das características seminais em bodes da raça Serrana. In CONGRESSO DE ZOOTECNIA "PROGRESSOS ZOOTÉCNICOS NOS PAÍSES DE LÍNGUA PORTUGUESA", 10., 2000, Vale de Santarém. Anais... Vale de Santarém: 2000. p.87.

TULI, R.K.; HOLTZ, W. Effect of glycerolization procedure and removal of seminal plasma on post-thaw survival and GOT-realease from boer goat spermatozoa. Theriogenology, v. 42, p.547-555, 1994.

VAZ DE MELO, M.I. Teste hipoosmótico na avaliação do sêmen eqüino. Belo Horizonte: Universidade Federal de Minas Gerais, 1999. 130p. Tese (Doutorado em Ciência Animal) - Universidade Federal de Minas Gerais, 1999.

VAZQUEZ, J.M.; MARTINEZ, E.A.; MARTINEZ, P. et al. Hipoosmotic swelling of boar spermatozoa compared to other methods for analysing the sperm membrane. Theriogenology, v.47, p.913-922, 1997.

VINHA, N.A. Variação estacional na produção e qualidade do sêmen de capra hircus (seasonal variation in the production and quality of goat sêmen). Arquivo da Escola de Veterinária UFMG, v.27, p.23-28, 1975.
Recebido: 18/01/05 Aprovado: 03/03/06 